\title{
РОЛЬ ГИПЕРЛОКАЛЬНЫХ МЕДИА В КОММУНИКАЦИИ МЕЖДУ ВЛАСТЬЮ И ОБЩЕСТВОМ В РОССИЙСКИХ РЕГИОНАХ
}

Гиперлокальные медиа в России, представленные главным образом городскими публичными группами на платформах социальных медиа, в последнее время становятся важным элементом локальной медиа сферы в российских регионах. Наряду с информированием жителей о событиях города, такие группы выступают площадками для общественных обсуждений, поддерживают местные сообщества и различные гражданские инициативы. Активное присутствие представителей власти на этих площадках делают группы важным пространством и каналом коммуникации между местной властью и обществом. На примере городских публичных групп в статье анализируется в какой степени низовые, непрофессиональные медиа инициативы могут обеспечивать коммуникацию между властью и гражданами в российских регионах и как такое вовлечение жителей в обсуждение городских вопросов влияет на локальное управление. Материалы интервью с владельцами и модераторами публичных групп семи российских городов, а также данные цифровых наблюдений показывают основные практики коммуникаций между жителями и представителями власти в пространстве социальных медиа, возможности таких групп мобилизовать общественные обсуждения. Гиперлокальные медиа обладают значительным потенциалом, чтобы выполнять роль канала коммуникации между гражданами и органами власти в регионах. В отличие от профессиональных масс медиа они обладают большей свободой в выборе тем и вопросов для обсуждения и в предоставлении возможности высказываться жителям города. Размер аудитории и популярность в городе делает эти медиа влиятельным каналом коммуникации в локальном пространстве. Факторы, влияющие на дальнейшее развитие таких групп, включают риск кооптации групп властью и признаки «псевдоучастия»,

Ольга Сергеевна Довбыш- к.с.н., преподаватель, Факультет коммуникаций, медиа и дизайна, Национальный исследовательский университет «Высшая школа экономики», Москва, Россия; постдок, Александровский институт, Университет Хельсинки, Финляндия. Электронная почта: olga.dovbysh@helsinki.fi 
когда возможности влиять на изменения и принятия решений ограничиваются темами и сферами, которые одобряет и поддерживает местная власть. Также сохраняется значительный разрыв между вовлечением граждан в «информационное участие» и их реальным участием в местном управлении. Наконец, на развитие городских групп в качестве канала коммуникации влияет их неустойчивость, желание собственника коммерциализировать проект, что приводит к преобладанию развлекательного и нейтрального, непроблемного контента.

Ключевые слова: гиперлокальные медиа, социальные медиа, российские регионы, общественная коммуникация

DOI: $10.17323 / 727-0634-2020-18-3-475-490$

В начале 2010-х гг. подавляющее большинство граждан считало, что они не способны влиять на решения, принимаемые властью, по важным для них проблемам (Петухов 2014). Однако с 2017 г. наблюдаются изменения в этом направлении, особенно на региональном уровне. Так, в 2019 г. $31 \%$ россиян, в основном молодые и образованные, считали, что могут влиять на принятие решений в своем регионе (Дергачев 2019). Какова роль цифровых медиа в этих изменениях?

Цифровые технологии значительно расширили возможности для коммуникации, в том числе прямой, между органами власти и гражданами через вебсайты, емейлы или платформы социальных медиа. Предполагается, что новые каналы коммуникации играют важное значение в определении и реконфигурации роли граждан в местном управлении, создают новые формы общественного участия в социальных и политических процессах (Chadwick 2008; Papacharissi 2010). В литературе выделяют нисходящие (top-down) и низовые (bottom-up) формы общественного участия и коммуникации с помощью цифровых медиа (De Cindio, Peraboni 2011). К первым относят различные (плат)формы цифрового и открытого управления, созданные органами власти «сверху» и направленные на процессы вовлечения граждан. К низовым относят инициативы, создаваемые и продвигаемые самими гражданами, иногда в партнерстве с общественными институтами.

В России цифровые нисходящие формы общественного участия представлены в первую очередь такими проектами как «Активный гражданин» в Москве (существует с 2014 г.) и других регионах, где жители могут участвовать в опросах по различным проблемам городского или регионального управления (Sokolov, Golovin 2019). Локальные массмедиа- местные газеты, телеканалы, онлайн СМИ-переживают нелегкие времена во многих странах. В России их положение осложняется различными формами государственного вмешательства в медиа, что приводит к подконтрольному положению и ограничению их функций. Кроме того, большинство локальных журналистов не адаптировались к цифровой среде, которая так и осталась для них вторичной (Erzikova, Lowrey 2017). Все это, а также рост популярности 
социальных сетей в качестве источника информации (Дергачев и др. 2019), способствует появлению в российских регионах альтернативных ${ }^{1}$ городских медиа- публичных групп в социальных сетях (далее- «паблики»).

Такие гиперлокальные медиа, как правило представляющие собой некоммерческие инициативы местных жителей, становятся все более важным элементом российской медиасреды. Наряду с информированием о событиях города, «паблики» выступают площадками для общественных обсуждений, поддерживают местные сообщества и различные гражданские инициативы. Растущий интерес и внимание местных властей, их активное присутствие на этих площадках, делают такие группы важным пространством общественного (со)участия и каналом коммуникации между органами власти и обществом. Поэтому справедливо рассматривать городские публичные группы в социальных сетях как одну из цифровых низовых форм общественного участия и коммуникации.

Однако «паблики» стоит понимать не только как примеры медийного активизма (Давыдов, Логунова 2018), но и с позиций выполняемых ими функций массмедиа в локальной медиасфере - функций посредничества между гражданами и политиками, представительства граждан перед различными властными структурами, обеспечения «голоса» общественности в политических и общественных обсуждениях, выстраивания конкретных политических решений и кампаний от имени общественности (McNair 2009). В этой статье я задаюсь вопросом, в какой степени низовые, непрофессиональные гиперлокальные медиаинициативы могут обеспечивать коммуникацию между властью и гражданами в российских регионах и как такое вовлечение жителей в обсуждение городских вопросов влияет на локальное управление.

\section{Цифровизация коммуникации между властью и обществом и «информационное участие»}

Несмотря на потенциал цифровых медиа, при более детальном анализе остается открытым вопрос, как именно такие медиа улучшают коммуникацию в обществе и ведет ли это к более эффективному управлению. Исследования в разных странах показывают, что с точки зрения расширения прав и возможностей граждан по-прежнему остается много ограничений (Bartoletti, Faccioli 2016). Во-первых, цифровые технологии не решают проблему равномерного и репрезентативного вовлечения граждан в коммуникацию. Сохраняется риск, что маргинализованные группы и индивиды останутся не включенными, в то время как активные и информированные граждане и группы будут влиять на принятие решений. Во-вторых, нет гарантии, что участие в обсуждениях с помощью цифровых медиа действительно будет

\footnotetext{
${ }^{1}$ Под альтернативными я имею ввиду их противоположность профессиональным массмедиа как в организации деятельности, так и в выборе тем для освещения.
} 
иметь какое-то влияние на управление. Возникает риск «псевдоучастия», направленного на дисциплинирование гражданской энергии за счет управления ею в цифровой среде. За это критикуют, например, платформу «Активный гражданин» в Москве, которая предлагает гражданам выбирать из уже готовых решений, а не разрабатывать решения самим (Заякин, Смагин 2018). В-третьих, режимы участия, опосредованные цифровыми медиа, различаются. Так, Жиль Мосс и Стивен Коулман предлагают классифицировать четыре типа граждан, в зависимости от их цифровых практик участия: совещающийся гражданин, который участвует в обсуждениях на форумах; гражданин-наблюдатель, который оценивает и контролирует работу властных структур и распространяет соответствующую информацию и данные; гражданин кликающий, который продвигает и подписывает различные петиции, и гражданин, представляющий «мудрость толпы» и участвующий в общественных краудсорсинговых инициативах (Moss, Coleman 2014).

Наконец, органы власти в разных странах и разных политических режимах рассматривают цифровые медиа в первую очередь как канал для однонаправленного распространения информации (Bartoletti, Faccioli 2016). Однако цифровые технологии позволяют гражданам быть не только получателями, но и производителями информации. Гражданская журналистика и другие формы участия в создании информации формируют так называемое «информационное участие», позволяющее гражданам представлять и доносить свои взгляды до правительства (Firmstone, Coleman 2015). Пока не до конца ясно, как эти взгляды могут приниматься во внимание и эффективно использоваться при принятии решений.

Наибольшее внимание исследователями уделяется низовым формам локального гражданского активизма, которые активно используют платформы социальных медиа и мессенджеры для коммуникации и мобилизации своих участников. Например, в России заметны низовые активистские проекты, связанные с проблемами городского развития и благоустройства городской среды (Tykanova, Khokhlova 2020), экологическими проблемами (Туровец 2019), честными выборами (Скокова 2016) и др. Для всех них характерна коммуникация через платформы социальных медиа и мессенджеры для распространения информации и координации действий. Как правило все эти проекты связаны с какой-то одной проблемой или событием. Для настоящего исследования важно обозначить низовые формы, обеспечивающие системную коммуникацию без привязки к какой-либо теме.

\section{Гиперлокальные медиа как низовая форма коммуникации между властью и обществом и их значение для локального управления}

Для анализа городских «пабликов» я использую понятие гиперлокальных медиа. Этот термин появился как одно из следствий «пространственного» 
поворота в медиаисследованиях (Falkheimer, Jansson 2006). Цифровые технологии повлияли на пересборку понятия локальных медиа. Локальность теперь может дробиться практически до бесконечно малого пространства, например, отдельной улицы или двора. Кроме того, новые технологии позволяют уйти от детерминированного географически понимания локальных медиа к их сборке через сообщества, в том числе сетевые, людей, объединенных общими ценностями и чувством принадлежности к определенному месту (Hess, Waller 2016). Дополнительным стимулом для формирования гиперлокальных медиа как отдельной группы являются возможности цифровых технологий создавать медиа не только профессиональным журналистам в редакциях, но и широкому кругу энтузиастов. Таким образом, гиперлокальные медиа определяют с одной стороны, как низовую, альтернативную профессиональным локальным масс медиа, форму медиа (Lindén et al. 2019), с другой-как набор определенных медийных практик, в том числе практик вовлечения граждан, способных создавать место и чувство принадлежности к нему (Rodgers 2018).

Роберт Парк писал, что «Местные новости- это то, из чего состоит демократия» (Park [1925] 1967: 85), отмечая, что таким образом мы (граждане) узнаем о себе как о (со)обществе, чтобы сформировать общественное мнение. Западные исследования, отмечая кризис профессиональных медиа, считают гиперлокальные медиа важным элементом медиасферы, особенно в демократически слабых режимах (Radcliffe 2015). При этом авторы предостерегают от упрощенного рассмотрения гиперлокальных медиа как еще одного механизма участия публики в общественных дебатах (Harte et al. 2018).

Низовая и любительская природа гиперлокальных медиа влияет на переосмысление того, какие новости и какая информация являются важными для обсуждения, как организованы эти обсуждения, что фактически приводит к «расширению и перекрытию общественной и частной повесток» (Papacharissi 2010: 149). Характер таких медиа позволяет им устанавливать тесные отношения с местной аудиторией и не только представлять различные группы, но и активно вовлекать их в коммуникацию за счет своей символической близости к ним (Barnett, Townend 2015). Поэтому при выборе тем или мест для освещения, практики гиперлокальных медиа сильно отличаются от практик профессиональных журналистов и масс медиа (Harte et al. 2018). Также такие медиа проявляют больше свободы в предоставлении возможности читателям высказываться и комментировать новости (Jangdal 2019).

Основными гиперлокальными медиа в России являются публичные группы, существующие на платформах социальных сетей (в первую очередь- «ВКонтакте»). Такие группы стали активно развиваться, начиная с 2010-х годов, вместе с развитием социальных медиа и широким проникновением интернета в российские регионы. К гиперлокальным медиа 
можно отнести и городские (urban) медиа- новые форматы независимых локальных медиа, направленные на формирование и поддержание городских сообществ (Ratilainen 2018; Нигматуллина 2018) и существующие главным образом в столицах российских регионов. Если в крупных городах присутствует разнообразие медийных источников, которые делают любительские группы второстепенными акторами, то в небольших населенных пунктах «паблики» выступают важным, а иногда и основным, источником местных новостей. Они публикуют как предложенные читателями, так и собственные новости, официальные пресс-релизы, слухи, жалобы, а также дают высказываться местным политикам и активистам, публикуют современные и исторические фотографии города. Обычно «паблики» ведут один или несколько модераторов. Часто это некоммерческие проекты, могут размещать рекламу, но лишь небольшое количество городских «пабликов» прибыльны (Dovbysh 2020). Отношения с традиционными медиа могут варьироваться от сотрудничества до полного игнорирования или даже конкуренции (Ibid).

\section{Методология исследования и источники данных}

В рамках исследования проведены экспедиции в российские города в 2017-2018 гг,, и собрано 82 полуструктурированных интервью с журналистами, редакторами традиционных массмедиа, блогерами, владельцами и модераторами городских «пабликов» и Telegram-каналов, чиновниками, отвечающими за взаимодействие с массмедиа. В статье я использую материалы 18 интервью с владельцами и модераторами городских «пабликов» из семи городов России: крупных городов- Тюмень (два интервью), Казань (три интервью) и малых- Переславль-Залесский (пять интервью), Арзамас (четыре интервью), Ковдор (одно интервью), Лобня (два интервью), Зеленоград (одно интервью).

Путеводитель по интервью охватывал различные вопросы об истории создания проекта, целях и мотивации создателя, о том, как формируется контент «паблика», о видении своего места в локальном медиаландшафте, в том числе относительно профессиональных массмедиа, о взаимодействии с местным правительством и др. Все интервью записаны и расшифрованы. Для анализа расшифровок использовался метод тематического анализа, который позволяет определять паттерны значений в выборке качественных данных (Braun et al. 2016).

Также источником для анализа послужили мои наблюдения за «пабликами» в городах, где проводились интервью. Я наблюдала за тем, какие темы размещаются, как разворачиваются обсуждения в комментариях под публикациями, кто участвует в этих обсуждениях (например, участвуют ли представители городской администрации, другие официальные лица, представители самих «пабликов»). Несмотря на то, что такие наблюдения носят 
дополнительный характер к основному источнику исследования, они помогают соотнести высказывания владельцев и модераторов «пабликов» с тем, что происходит в самих «пабликах», понять, как они «живут».

\section{Городские «паблики» как канал коммуникации между жителями и властью}

Данные показывают, что городские «паблики» являются важным каналом коммуникации для местных властей. И хотя степень внимания со стороны чиновников варьируется, во всех городах выборки городские «паблики» так или иначе вовлечены в распространение официальной информации. Это могут быть как публикация постов на основе официальных пресс-релизов городской администрации, МВД, прокуратуры и других структур, «репосты» официальных СМИ, так и эксклюзивные материалы, когда чиновники дают интервью или комментарии. Кроме того, власти могут использовать «паблики» для проведения опросов и голосований (чаще всего по проблемам городского благоустройства). При этом сами респонденты отмечают ограниченную объективность таких опросов:

Там просто люди... кому ближе к дому, касаемо какой-то территории. То есть кому ближе к дому. Или кому-то это вообще неважно. Есть история про то, что кто-то пытается разослать всем друзьям, попросить проголосовать за это. Вроде бы это какой-то вес имеет, процентное содержание понять хотя бы. Но фактически это могут быть люди даже не местные. Поэтому это такая статистика сомнительная (основатель и владелец городского паблика ВКонтакте, малый город).

Другой формой коммуникации являются ответы представителей властей на комментарии жителей и участие в обсуждениях непосредственно через городские медиа. Например, группа «ВКонтакте» «Весь Арзамас» проводит прямые эфиры с мэром города, в ходе которых подписчики могут передать ему свои вопросы ${ }^{1}$. Несмотря на тренд на цифровизацию и создание вебсайтов местных органов власти и бюджетных учреждений, сохраняется запрос на межличностную коммуникацию, даже в опосредованной социальными медиа форме, потому что «люди хотят говорить с людьми»:

Когда люди, например, ищут время работы врача-у них не появляется в голове, что можно зайти на сайт больницы, там есть расписание, они просто пишут- «Когда у нас невролог работает?» И мы отвечаем, я лично отвечаю (представитель городского паблика ВКонтакте, малый город).

Городские администрации нередко создают собственные официальные группы или официальные страницы мэров в социальных сетях, однако в таких группах комментариев и обсуждений практически нет и политика

\footnotetext{
${ }^{1}$ Ссылки на соответствующие страницы «пабликов» хранятся у автора.
} 
замалчивания («банов») жесткая. Поэтому основные обсуждения остаются именно в пространстве городских независимых медиа. Создатели «пабликов» отмечали, что среди целей их проектов- возможность свободного общения:

Другие ресурсы не любят критики, поэтому небольшое возмущениесразу удаляют в бан. Меня в основной группе администрации забанили за то, что я не по теме высказался: там была дорога, а я что-то про канализацию сказал. Там жестко нельзя критиковать. А мы говорим, что у нас можно все, только не переходите на личности (основатель и модератор городского паблика ВКонтакте, малый город).

Тем не менее степень свободы обсуждений варьируется и зависит в первую очередь от решения владельца или модератора, которые имеют возможность в одностороннем порядке блокировать участников или удалять комментарии. Чаще всего это касается либо ненормативной лексики и оскорблений, либо личных просьб героев публикаций удалить материал, либо политических тем. Иногда это обозначается как стремление «избежать негатива/негативной информации»:

У нас нет задачи насолить администрации. Так, говорим о каких-то нехороших вещах, но особо пальцем не тыкаем. У нас нет такой задачи. Есть группки политизированные. Потому что когда идёт какая-то... Ткни пальцем - это явно кому-то выгодно. У нас нет такой задачи, потому что нам это не нужно. У нас нет интереса к политике, и мы ни к кому не принадлежим. <...> Либо личностные какие-то вещи, когда они касаются людей. Если человек попросит удалить- мы удаляем. Что-то случилось, человек пишет: «Мне не хочется, чтобы об этом говорили, удалите, пожалуйста,»- мы удаляем. <...> Политику мы удаляем (владелец городского паблика ВКонтакте, малый город).

Наконец, третьей практикой коммуникации является самостоятельное просматривание страниц местными чиновниками. Такой мониторинг позволяет им выявлять проблемные сферы в городе и оперативно на них реагировать. Например, одна из респонденток, сотрудница городской администрации, отмечала, что ежедневно просматривает ленты главных городских «пабликов» и, если видит сообщения о проблемах - пересылает своим коллегам в соответствующие департаменты. Вместе с тем мониторинг содержания «пабликов» позволяет отслеживать настроение среди жителей, основные направления критики в отношении политиков, особенно накануне выборов. Мониторинг содержания городских «пабликов» чиновниками как на местном, так и на региональном уровне является довольно устоявшейся практикой, о существовании которой знают и представители медиа:

...это не секрет, что это на областном уровне всё мониторится. Видимо, у них с области это спускается - и кто-то получает по башке. Возможно, тот, кто работает с областью, с регионом (представитель городского паблика ВКонтакте, малый город). 
Помимо предоставления канала и площадки для коммуникации, модераторы и владельцы «пабликов» могут занимать более активную позицию и использовать свой медийный ресурс для усиления и активизации коммуникации в местном сообществе. Активность позиции «паблика» напрямую зависит от интересов и мотиваций владельца/модератора, его ресурсов (временных, финансовых). Наиболее типичный случай такого участия, когда сам «паблик» (его владелец и/или модераторы) являются инициаторами и участниками общественных инициатив. Часто это касается экологических проектов и протестов. Например, один из «пабликов» Переславля-Залесского активно выступал против застройки территории рядом с Плещеевым озером и действовал не только как канал распространения информации, но и собирал людей для общественных слушаний, составлял документы и запросы.

Поскольку «паблики» являются низовой инициативой, незарегистрированной как НКО или как СМИ, их власть в местном сообществе базируется скорее на имеющемся медийном ресурсе (аудитория, возможность огласки), чем на легитимном праве совершать такие действия. Так, в одном из малых городов местная администрация и городской «паблик» договорились о следующем взаимодействии: если «паблик» получает информацию о проблеме от жителей, прежде чем быть опубликованной, информация отправляется в городскую администрацию. У последней есть сутки, чтобы отреагировать, тогда информация появляется в «паблике» с учетом этого ответа. В противном случае- в первоначальном виде:

Если приходит негатив- мы с ними сотрудничаем. Есть условия работы, они должны ответить в течение суток. Если в течение суток не отвечают - то публикуется без редакции, и тогда будет большой срач (муж., модератор городского паблика ВКонтакте, малый город).

Другой пример касается представительства интересов жителей. Городская группа «Зеленоград.ру» создана и ведется командой вебсайта с одноименным названием, который зарегистрирован как электронное СМИ. Статус СМИ позволяет отправлять запросы в городскую администрацию и другие учреждения, получать полные и оперативные ответы, чем на запросы физических лиц. Таким образом, портал предлагает жителям выступать их представителем во взаимодействии с различными инстанциями, а также предоставлять медийную поддержку (портал берет плату за эту услугу). Владелец проекта утверждает, что даже без регистрации СМИ, у них была бы возможность таких действий:

Когда за тобой пара тысяч подписей реальных людей, то на твой запрос отвечают быстро, даже когда он от физлица. И наоборот: просто запрос СМИ, когда ведомство не считает его игнорирование угрозой для себя, часто не работает сам по себе (владелец городского паблика ВКонтакте и вебсайта, малый город). 


\section{Кооптация властями и долгосрочная устойчивость гиперлокальных медиа}

Несмотря на потенциал гиперлокальных медиа как канала для коммуникации между гражданами и органами власти в регионах, стоит также обозначить и ряд ограничивающих факторов. Первый связан с критической оценкой функций социальных медиа в недемократических и гибридных режимах. Речь идет о проактивной кооптации, когда социальные медиа фактически выполняют функции поддержания режима (Gunitsky 2015). Вместо «негативного контроля» через блокировки, цензуру и давление, стратегии кооптации направлены на использование социальных медиа властными структурами как доступного и сравнительно дешевого источника данных об общественных настроениях, проблемах и жалобах. Привлечение внимания жителей к обсуждению проблем в социальных сетях, позволяет не доводить их до более активных протестов.

Можно отметить следующие свидетельства кооптации или ее попыток. Например, разделение тем и дискурсов, освещение и обсуждение которых власти приветствуют и поддерживают и, наоборот, блокируют. Так, к поддерживаемым относятся темы ЖКХ, городского благоустройства, проблемы образования. К нежелательным-всё, что касается выборов, если речь не идет о поддержке основного кандидата, оппозиционные политики, прямая критика чиновников, коррупция. Одновременно с этим городские администрации стремятся налаживать «рабочие» и «дружественные» отношения с «пабликами» ${ }^{1}$. Например, проводят рабочие встречи и круглые столы с участием модераторов и владельцев, предоставляют информацию, часто уникальную. В результате «паблики» становятся более аккуратны в выборе тем и тона повествования. Становятся более нейтральны, «уходят от политики». Фактически это приводит или может приводить к смещению функций «паблика» от представительства граждан к представительству властных структур.

Другой ограничивающий фактор для общественной коммуникации кроется в их низовой и любительской природе и проблеме долгосрочной устойчивости гиперлокальных медиа (Tenor 2018). Респонденты указывают, что создавали и развивали свои проекты как хобби, не ожидая популярности и большого количества подписчиков. Поэтому существуют значительные риски для дальнейшего развития этих инициатив. Владелец может передать или продать «паблик» другому человеку, который будет преследовать другие цели, или просто забросить проект. Наиболее частая ситуация, когда владелец начинает коммерциализировать проект. Это

\footnotetext{
1 Другие, более явные формы контроля, например, через финансирование или права собственности распространены реже, но тоже встречаются.
} 
влияет на контент «паблика», который становится более ориентирован на просмотры и лайки, чем на местное сообщество.

Еще один ограничивающий фактор связан с разной степенью вовлечения жителей в «информационное участие» и в другие совещательные формы в местном управлении. Общественные слушания и встречи с представителями власти, подготовка и курирование официальных запросов и другие активности привлекают по сравнению с обсуждениями в «пабликах» намного меньше участников:

Все поговорили, но в итоге дошло не очень много людей до обсуждений. Три дня там было обсуждение. Писали, что придут чуть ли не 150 человек. Дошло в районе 20 - все те же самые люди ходят в реале, чтобы проголосовать, что-то конкретно высказать. Диванные войска (модератор городского паблика ВКонтакте, малый город).

Несмотря на увеличивающееся значение цифровых медиа для участия граждан в местном управлении, традиционные «оффлайновые» формы участия все еще занимают центральное место (Firmstone, Coleman 2015; Bartoletti, Faccioli 2016). То есть даже при возможности обсуждения вопроса в интернете, решающее значение будет иметь участие в реальной встрече или написание официального запроса.

Совокупность этих факторов создает риски «псевдоучастия»-ситуации, когда городские «паблики», с одной стороны, действительно формируют пространство для коммуникации между гражданами и представителями власти, мотивируют и мобилизуют жителей включаться в обсуждение и решение местных проблем, предоставляют возможность голоса различным локальным группам и сообществам. С другой стороны, пространство социальных сетей остается «вещью в себе» и позволяет влиять на изменения только в тех сферах, которые одобряются и поддерживаются властью. При этом иллюзия общественной коммуникации и возможности влиять на принятие местных решений снимает риски возникновения более активных протестов и поддерживает стабильность локальной власти и ее статус кво.

\section{Заключение}

Цифровые технологии, в частности платформы социальных медиа, создают новые возможности для коммуникации внутри сообщества и с представителями власти, а также способствуют усилению роли граждан в местном управлении (Chadwick 2008). Гиперлокальные медиа, представляющие собой низовые, некоммерческие и часто непрофессиональные медиа инициативы местных жителей, становятся каналами и площадками «информационного участия». Наряду с (плат)формами вовлечения граждан, созданными государством, низовые инициативы играют важную роль, поскольку предоставляют жителям возможность не только быть 
получателями информации «сверху», но и самим участвовать в определении и формировании повестки.

Пример городских «пабликов» в российских регионах демонстрирует как низовые инициативы могут выступать каналом коммуникации между властью и обществом в недемократических режимах. За счет близости к жителям и простоте доступа городские «паблики» позволяют вовлекать больше жителей и социальных групп в обсуждение вопросов местного управления, привлекать внимание к менее видимым проблемам. При отсутствии независимых профессиональных массмедиа, городские «паблики» обладают определенной символической властью: возможность распространения нежелательной для местных властей информации заставляет последних реагировать на эти медиаинициативы и взаимодействовать с ними. Однако стратегии кооптации со стороны властных структур и желание перетянуть «паблики» на свою сторону создают риски «псевдоучастия» и смещения фокуса последних с поддержки местных сообществ на поддержку местных чиновников.

\section{Выражение признательности}

Эта статья является частью исследования «История развития интернета в российских регионах», выполненного при финансовой поддержке «Фонда образовательных инноваций» НИУ ВШЭ вместе с командой преподавателей и студентов НИУ ВШЭ и клуба любителей интернета и общества. Я благодарю Аллу Болотову за интервью с владельцем «паблика»в Ковдоре и клуб любителей интернета и общества за интервью с представителями «пабликов» в Лобне.

\section{Список источников}

Давыдов С.Г., Логунова О.С. (2018) Сообщества московских районов в социальных медиа: контент и его модерация. Мониторинг общественного мнения: экономические и сочиальные перемены, (1):204-221.

Заякин А., Смагин А. (2018) Продам свой голос за свитшот. Новая Газета. Доступно по ссылке: https://clck.ru/Pkpc3 (дата обращения: 5 июля 2020).

Дергачев В. (2019) Каждый пятый россиянин поверил в свое влияние на решения властей. РБК. Доступно по ссылке: https://clck.ru/PkpdQ (дата обращения: 5 июля 2020).

Дергачев В., Кузнецова Е., Истомина М. (2019) Четверть россиян потеряли доверие к телевидению за десять лет. РБК. Доступно по ссылке: https:/clck.ru/PkpeZ (дата обращения: 5 июля 2020).

Нигматуллина К.Р. (2018) Гибридная повестка новых городских медиа: между локальным и федеральным (на примере медиапространства Санкт-Петербурга. Знак: проблемное поле медиаобразования, 4 (30): 224-235.

Петухов Р.В. (2014) Локальные сообщества и гражданский активизм. Мониторинг общественного мнения: экономические и сочиальные перемены, 122 (4): 60-71.

Скокова Ю.А. (2016) Динамика развития общественного движения наблюдателей на выборах: результаты исследования 2011-2016 гг. Журнал социологии и соииальной антропологии, 19 (3): 65-79. 
Туровец М. (2019) Почему у Шиеса получается. Как устроены экологические протесты в России. Сноб. Доступно по ссылке: https://snob.ru/entry/180991/ (дата обращения: 5 июля 2020).

Barnett S., Townend J. (2015) Plurality, Policy and the Local. Journalism Practice, 9 (3):332-349.

Bartoletti R., Faccioli F. (2016) Public Engagement, Local Policies, and Citizens' Participation: An Italian case study of civic collaboration. Social Media + Society, 2 (3): 1-11.

Braun V., Clarke V., Weate P. (2016) Using Thematic Analysis in Sport and Exercise Research. In: B. Smith, A.C. Sparkes (eds.) Routledge Handbook of Qualitative Research in Sport and Exercise. London: Routledge: 213-227.

Chadwick A. (2008) Web 2.0: New Challenges for the Study of E-democracy in an Era of Informational Exuberance. I/S: A Journal of Law and Policy for the Information Society, (5): 9-42.

De Cindio F., Peraboni C. (2011) Building Digital Participation Hives: Toward a Local Public Sphere. In: M. Foth, L. Forlano, C. Satchell, M. Gibbs (eds.) From Social Butterfly to Engaged Citizen. Cambridge, MA: MIT Press:93-113.

Dovbysh O. (2020) Do Digital Technologies Matter? How Hyperlocal Media is Re-Configuring the Media Landscape of a Russian Province. Journalism, https://doi.org/10.1177/1464884920941966.

Erzikova E., Lowrey W. (2017) Russian Regional Media: Fragmented Community, Fragmented Online Practices. Digital Journalism, 5 (7): 919-937.

Falkheimer J., Jansson A. (2006) Geographies of Communication: The Spatial Turn in Media Studies. Göteborg: Nordicom.

Firmstone J., Coleman S. (2015) Public Engagement in Local Government: The Voice and Influence of Citizens in Online Communicative Spaces. Information, Communication \& Society, 18 (6): 680-695.

Gunitsky S. (2015) Corrupting the Cyber-commons: Social Media as a Tool of Autocratic Stability. Perspectives on Politics, 13 (1): 42-54.

Harte D., Howells R., Williams A. (2018) Hyperlocal Journalism: The decline of local newspapers and the rise of online community news. London: Routledge.

Hess K., Waller L. (2016) Local Journalism in a Digital World. London: Palgrave MacMillan. Jangdal L. (2019) Local Democracy and the Media. Nordicom Review, 40 (s2): 69-83.

Lindén C. G., Hujanen J., Lehtisaari K. (2019) Hyperlocal Media in the Nordic Region. Nordicom Review, 40 (s2): 3-13.

McNair B. (2009) Journalism and Democracy. In: K. Wahl-Jorgensen, T. Hanitzcsh (eds.) The Handbook of Journalism Studies. New York: Routledge: 237-249.

Moss G., Coleman S. (2014) Deliberative Manoeuvres in the Digital Darkness: E-Democracy Policy in the UK. The British Journal of Politics and International Relations, 16 (3): 410-427. Papacharissi Z. (2010) A Private Sphere: Democracy in a Digital Age. Cambridge: Polity.

Park R.E. (1967) The Natural History of the Newspaper. In: R.E. Park, E. W. Burgess, R.D. McKenzie (eds.) The City. Chicago: University of Chicago Press: 80-98.

Radcliffe D. (2015) Where are we now? UK hyperlocal media and community journalism in 2015. London: Nesta.

Ratilainen S. (2018) Digital Media and Cultural Institutions in Russia: Online Magazines as Aggregates of Cultural Services. Cultural Studies, 32 (5): 800-824.

Rodgers S. (2018) Roots and Fields: Excursions Through Place, Space, and Local in Hyperlocal Media.Media. Culture \& Society, 40 (6): 856-874.

Sokolov A., Golovin Y. (2019) Interaction of Authorities and Citizens: What Opportunities Does the Internet Provide (on the Example of the Yaroslavl Region). In: International Conference on Digital Transformation and Global Society. Cham: Springer: 133-151.

Tenor C. (2018) Hyperlocal News and Media Accountability. Digital Journalism, 6 (8): 1064-1077. Tykanova E., Khokhlova A. (2020) Grassroots Urban Protests in St. Petersburg: (Non-) Participation in Decision-Making About the Futures of City Territories. International Journal of Politics, Culture, and Society, (33): 181-202. 
Olga Dovbysh

\title{
HYPERLOCAL MEDIA AS A COMMUNICATION CHANNEL BETWEEN STATE AND SOCIETY IN RUSSIA'S REGIONS
}

\begin{abstract}
Hyperlocal media in Russia, represented mainly by city public groups in social network websites, have recently become important elements of local media ecosystems in Russia's regions. Along with the dissemination of information on local news and affairs, these groups act as platforms for public discussions and support community initiatives and local activism. The active involvement of local state bodies in these groups has made these sites important spaces of public participation as well as a communication channel between city administrations and local society. Taking the example of city public groups, this article explores to what extent non-professional and noncommercial media initiatives can enhance public engagement and citizen participation in local governance as well as to what extent these digital media can serve as communication channels between state bodies and citizens in Russian regions. The empirical data includes eighteen interviews with owners and moderators of public city groups, conducted during author's fieldwork in seven Russia's cities in 2017-2018. Additionally, the data include digital observations in social media and observations at an industry conference for media practitioners. Based on the empirical evidence, I reveal the main communication practices utilized by these groups to provide communication and interaction between citizens and authorities. Also, I explore the main opportunities for these groups to act as actors and facilitators of public initiatives. Grassroots digital media is showing growing potential for public engagement. Compared to professional local newsrooms, they demonstrate higher freedom in the selection of topics and issues for public discussion. Also, hyperlocal media offer wider opportunities for local citizens to express their opinions by commenting and publishing own materials. Constraining factors include co-optation strategies of state bodies, evidence of 'pseudoparticipation' and a significant gap between the share of people involved in 'information engagement' and in offline activities.
\end{abstract}

Key words: hyperlocal media, Russian regions, civic engagement, bottom-up civic initiatives

DOI: $10.17323 / 727-0634-2020-18-3-475-490$

\section{References}

Barnett S., Townend J. (2015) Plurality, Policy and the Local. Journalism Practice, 9 (3): $332-349$.

Olga Dovbysh-Cand. Sci. (Soc.), lecturer, National Research University Higher School of Economics, Moscow, Russian Federation; postdoctoral researcher, Aleksanteri Institute, University of Helsinki, Finland. Email: olga.dovbysh@helsinki.fi 
Bartoletti R., Faccioli F. (2016) Public Engagement, Local Policies, and Citizens' Participation: An Italian Case Study of Civic Collaboration. Social Media + Society, 2 (3): 1-11.

Braun V., Clarke V., Weate P. (2016) Using Thematic Analysis in Sport and Exercise Research. In: B. Smith, A. C. Sparkes (eds.) Routledge Handbook of Qualitative Research in Sport and Exercise. London: Routledge: 213-227.

Chadwick A. (2008) Web 2.0: New Challenges for the Study of E-democracy in an Era of Informational Exuberance. I/S: A Journal of Law and Policy for the Information Society, (5): 9-42.

Davydov S., Logunova O. (2018) Soobshchestva moskovskikh rayonov v sotsial'nykh media: kontent i ego moderatsiya [Moscow District Social Media Communities: Content and its Moderation]. Monitoring obshchestvennogo mneniya: ekonomicheskie i sotsial'nye peremeny [Monitoring of Public Opinion: Economic and Social Changes], (1):204-221.

De Cindio F., Peraboni C. (2011) Building Digital Participation Hives: Toward a Local Public Sphere. In: M. Foth, L. Forlano, C. Satchell, M. Gibbs (eds.) From Social Butterfly to Engaged Citizen. Cambridge, MA: MIT Press:93-113.

Dergachev V. (2019) Kazhdiy pyatiy rossiyanin poveril v svoe vliyanie na reshenie vlastey [Every Fifth Russian Believed in their Influence on the Authorities' Decisions]. RBC. Available at: https://clck.ru/PkpdQ (accessed 5 July 2020).

Dergachev V., Kuznetsova Y., Istomina M. (2019) Chetvert' Rossian poteruali doverie k televideniyu za desyat' let [A Quarter of Russians Have Lost Trust in TV over the last Decade]. RBC. Available at: https://clck.ru/PkpeZ (accessed 5 July 2020).

Dovbysh O. (2020) Do Digital Technologies Matter? How Hyperlocal Media is Re-Configuring the Media Landscape of a Russian Province. Journalism, https://doi. org/10.1177/1464884920941966.

Erzikova E., Lowrey W. (2017) Russian Regional Media: Fragmented Community, Fragmented Online Practices. Digital Journalism, 5 (7):919-937.

Falkheimer J., Jansson A. (2006) Geographies of Communication: The Spatial Turn in Media Studies. Göteborg: Nordicom.

Firmstone, J., Coleman, S. (2015). Public Engagement in Local Government: The Voice and Influence of Citizens in Online Communicative Spaces. Information, Communication \& Society, 18 (6): 680-695.

Gunitsky S. (2015) Corrupting the Cyber-commons: Social Media as a Tool of Autocratic Stability. Perspectives on Politics, 13 (1):42-54.

Harte D., Howells R., Williams A. (2018) Hyperlocal Journalism: The Decline of Local Newspapers and the Rise of Online Community News. London: Routledge.

Hess K., Waller L. (2016) Local Journalism in a Digital World. London: Palgrave MacMillan.

Jangdal L. (2019) Local Democracy and the Media. Nordicom Review, 40 (s2): 69-83.

Lindén C. G., Hujanen J., Lehtisaari K. (2019) Hyperlocal Media in the Nordic Region. Nordicom Review, 40 (s2):3-13. 
McNair B. (2009) Journalism and Democracy. In: K. Wahl-Jorgensen, T. Hanitzcsh (eds.) The Handbook of Journalism Studies. New York: Routledge: 237-249.

Moss G., Coleman S. (2014) Deliberative Manoeuvres in the Digital Darkness: E-Democracy Policy in the UK. The British Journal of Politics and International Relations, 16 (3): 410-427.

Nigmatullina K. (2018) Gibridnaya povestka novyh gorodskih media: mezhdu lokal'nym i federal'nym (na primere mediaprostranstva Sankt-Peterburga) [The Hybrid Agenda of New Urban Media: Between Local and Federal (The Case of Media in St.Petersburg)]. Znak: problemnoe pole mediaobrazovaniya [Znak: The Problematic Field of Media Education], 4 (30): 224-235.

Papacharissi Z. (2010) A Private Sphere: Democracy in a Digital Age. Cambridge: Polity.

Park R.E. (1967) The Natural History of the Newspaper. In: R.E. Park, E. W. Burgess, R.D. McKenzie (eds.) The City. Chicago: University of Chicago Press: 80-98.

Radcliffe D. (2015) Where are We Now? UK Hyperlocal Media and Community Journalism in 2015. London: Nesta.

Ratilainen S. (2018) Digital Media and Cultural Institutions in Russia: Online Magazines as Aggregates of Cultural Services. Cultural Studies, 32 (5): 800-824.

Rodgers S. (2018) Roots and Fields: Excursions Through Place, Space, and Local in Hyperlocal Media.Media. Culture \& Society, 40 (6): 856-874.

Skokova Yu. A. (2016) Dinamika razvitiya obsxhestvennogo dvizheniya nabludatelei na vyborah: rezul'taty issledovaniya 2011-2016 gg. [Development Dynamic of Public Movement for Observers at the Elections: Results of Research 2011-2016]. Zhurnal sotsiologii i sotsialnoy antropologii [The Journal of Sociology and Social Anthropology], 19 (3): 65-79.

Sokolov A., Golovin Y. (2019) Interaction of Authorities and Citizens: What Opportunities Does the Internet Provide (on the Example of the Yaroslavl Region). In: International Conference on Digital Transformation and Global Society. Cham: Springer: 133-151.

Tenor C. (2018) Hyperlocal News and Media Accountability. Digital Journalism, 6 (8): 1064-1077.

Turovets M. (2019) Pochemu u Shiesa poluchetsya. Kak ustrieny ekologicheskie protest v Rossii [Why does it Work in Shiyes? How Ecological Protests in Russia are Organized]. Snob. Available at: https://snob.ru/entry/180991/ (accessed 5 July 2020).

Tykanova E., Khokhlova A. (2020) Grassroots Urban Protests in St. Petersburg: (Non-) Participation in Decision-Making About the Futures of City Territories. International Journal of Politics, Culture, and Society, (33): 181-202.

Zayakin A., Smagin A. (2018) Prodam svoy golos za svitshot [Sell My Voice for a Sweatshirt]. Novaya Gazeta [New Newspaper]. Available at: https://clck.ru/Pkpc3 (accessed 5 July 2020). 